\title{
HACIA EL ESTABLECIMIENTO DE UNA FÓRMULA NORMATIVA SUSTENTABLE PARA INCENTIVAR LA UTILIZACIÓN DE LOS RECURSOS GENÉTICOS*
}

\author{
Dominique Hervé Espejo ${ }^{* *}$
}

\begin{abstract}
RESUMEN
Existen diversos instrumentos internacionales que se aplican tanto a la regulación de los recursos genéticos como de la propiedad intelectual asociada a las tecnologías que los utilizan. En la actualidad se están desarrollando una serie de iniciativas tendientes a integrar y coordinar ambos tipos de instrumentos con el objeto de que los países, al momento de definir sus leyes y políticas en la materia, consideren e incorporen los elementos y obligaciones provenientes de ambos regímenes jurídicos. Chile todavía no adopta una regulación nacional para el acceso a sus recursos genéticos, por lo que tiene la oportunidad de integrar su legislación en esta materia con su legislación de propiedad intelectual, logrando un régimen jurídico que favorezca tanto el desarrollo tecnológico nacional como la protección de sus recursos.
\end{abstract}

\section{DESARROLLO SUSTENTABLE - RECURSOS GENÉTICOS - BIOTECNOLOGÍA}

\section{Towards the establishment of a sustainable normative formula to encourage the use of genetic resources}

\begin{abstract}
There are diverse international instruments that apply to both the regulation of genetic resources and the intellectual property attached to the technologies that use those resources. At the present moment, a series of initiatives are being developed, determined to integrate and coordinate both kinds of instruments, aiming to make countries consider and integrate elements and obligations from both legal regimes, when defining their laws and policies on the subject. Chile has not yet adopted a domestic regulation regarding the access to its genetic resources; consequently it still has the opportunity to integrate its legislation on the matter with its intellectual property legislation, in order to attain a legal regime that favors both the national technological development as well as the protection of its resources.
\end{abstract}

\section{SUSTAINABLE DEVELOPMENT - GENETIC RESOURCES - BIOTECHNOLOGY}

* Este trabajo se basa en la investigación desarrollada por la autora en el contexto de los siguientes proyectos: Proyecto Fondecyt $\mathrm{N}^{\circ} 1020182$ “Aspectos jurídicos del concepto de Desarrollo Sustentable y sus implicancias para los países en desarrollo, especialmente Chile" y el proyecto de la IUCN titulado "Synergetic Implementation: Coordinated National Implementation of Access and Benefit Sharing Issues-CBD, Biosafety Protocol, ITPGRFA and relevant IPR instruments".

** Abogada, Master en Derecho Ambiental, Profesora e investigadora de la Facultad de Derecho de la Universidad Diego Portales, Santiago de Chile (dominique.herve@prof.udp.cl). Artículo recibido el 25 de septiembre de 2006 y aceptado para su publicación por el Comité Editorial el 4 de mayo de 2007. 


\section{INTRODUCCIÓN}

$\mathrm{H}$ asta hace muy poco tiempo la manipulación genética se efectuaba a través de métodos y procedimientos tradicionales, usados por el hombre desde hace cientos de años. ${ }^{1}$ El vertiginoso desarrollo de la biotecnología moderna ${ }^{2}$ (o de la "ingeniería genética"), a partir de la década de los setenta, cambió por completo este panorama, dotando al material genético de un valor propio (en gran medida independiente del organismo que lo contiene) que le atribuyó una tremenda importancia económica, social y política a nivel mundial. De este modo, la consideración del material genético como "recurso" implica claramente la comprensión y valoración de su importancia práctica para la humanidad y un reconocimiento de la riqueza existente en la diversidad biológica a nivel de genes.

En el ámbito internacional, los primeros esfuerzos normativos para abordar el tema de los recursos genéticos fueron realizados por la Organización de las Naciones Unidas para la Agricultura y la Alimentación (FAO), a través del Compromiso Internacional sobre Recursos Fitogenéticos (1983). Sin embargo, debido a la falta de experiencia en la regulación de este tipo de recursos y a diversos conflictos de intereses, en una primera instancia las disposiciones del Compromiso Internacional no llegaron a tener un carácter vinculante. Sólo a partir de la entrada en vigencia de la Convención de la Diversidad Biológica (CDB), el año 1993, se originó un cambio sustantivo en el escenario internacional del manejo de los recursos genéticos. Además de reconocer expresamente el derecho soberano de los Estados sobre sus recursos naturales la CDB estableció, como consecuencia necesaria de dicho reconocimiento, que "la facultad de regular el acceso a los recursos genéticos incumbe a los gobiernos nacionales y está sometida a la legislación nacional". ${ }^{3}$ Sobre dicha base, las disposiciones de la CDB crearon una fórmula normativa destinada a incentivar la conservación y la utilización sostenible de los recursos genéticos, combinando la regulación del acceso a dichos recursos con un reparto justo y equitativo de los beneficios derivados de su utilización. ${ }^{4}$

Agradezco los comentarios a un borrador previo de este trabajo, en una sesión dedicada a la discusión del mismo, por parte de Jorge Bermúdez, profesor de la Facultad de Derecho de la Universidad Católica de Valparaíso; Ximena Fuentes, profesora de la Facultad de Derecho de la Universidad Adolfo Ibañez; y de los investigadores del Centro de Investigaciones Jurídicas de la Facultad de Derecho de la Universidad Diego Portales.

${ }^{1}$ Se refiere a la llamada "biotecnología tradicional" que comprende las diversas técnicas utilizadas a lo largo de la historia, mediante el cruzamiento de organismos cercanos en procesos relativamente largos, que generan nuevas variedades genéticas.

${ }^{2}$ Se llama biotecnología moderna a la tecnología mediante la cual se crean nuevas variedades genéticas a través de la introducción directa de genes de especies muy diferentes, o la introducción, supresión o multiplicación de genes de la misma especie, en procesos biotecnológicos que se caracterizan por su rapidez, y que dan origen a los llamados "organismos genéticamente modificados".

3 Artículo 15.1 de la CDB.

${ }^{4}$ Cabe señalar que en el año 2000 se adopta un Protocolo de la CDB con el objeto de regular el movimiento transfronterizo, el tránsito, la manipulación y la utilización de todos los organismos vivos modificados (resultantes de la biotecnología moderna) que puedan tener efectos adversos para la conservación y utilización 
Algunos años más tarde (2001), luego de un largo proceso de debate y negociación y, en gran parte, gracias a la determinante influencia de la CDB y al cambio radical originado por sus normas, el Compromiso Internacional sobre Recursos Fitogenéticos de la FAO fue reformulado con el propósito de constituirse en el instrumento jurídico encargado de regular el manejo internacional de los recursos genéticos para la agricultura y la alimentación. ${ }^{5}$ De este modo, existen en la actualidad dos instrumentos internacionales jurídicamente vinculantes que regulan específicamente el tema del acceso a los recursos genéticos. ${ }^{6}$

Por otra parte, diversos instrumentos internacionales en materia de propiedad intelectual son también relevantes para un régimen jurídico de acceso a los recursos genéticos y distribución de sus beneficios. ${ }^{7}$ En efecto, la utilización de los recursos genéticos tiene una dependencia tan grande de la tecnología necesaria para llevarla a efecto que casi podría decirse que biotecnología y recursos genéticos son lo mismo (en el caso del material genético, más que en ningún otro, sin la tecnología requerida para su utilización la materia prima no tiene mayor valor comercial). Además, si bien es cierto que para acceder al material genético es necesario tener algún tipo de acceso al recurso biológico que lo contiene, la prospección de material genético, determinada por el posible valor comercial del mismo, depende mucho más de la información asociada al recurso que de su materialidad.

Es así como los países deben, al momento de establecer sus leyes y políticas en materia de recursos genéticos, considerar tanto los elementos y obligaciones provenientes de los instrumentos relacionados con la conservación y uso sustentable de la biodiversidad (CDB, Protocolo de Cartagena, TI/RFAA) como aquellos provenientes de la propiedad intelectual asociada a las tecnologías que la utilizan (TRIPS/OMC, OMPI, UPOV).

En este contexto, el antiguo debate en torno al principio de soberanía y el derecho de los Estados a explotar sus propios recursos naturales adquiere nuevamente relevan-

sostenible de la biodiversidad, teniendo también en cuenta los riesgos para la salud humana (Protocolo de Cartagena sobre Seguridad de la Biotecnología). El Protocolo entra en vigencia en septiembre de 2003.

${ }^{5}$ El Tratado Internacional sobre los Recursos Fitogenéticos para la Alimentación y la Agricultura (TI/RFAA) entra en vigencia en junio de 2004, luego que cuarenta países lo ratificaron, según lo dispuesto por su artículo 28 .

${ }^{6}$ No nos referimos aquí al Protocolo de Cartagena puesto que éste no regula el acceso a los recursos genéticos sino que los riesgos para la biodiversidad derivados de la utilización y liberación de organismos modificados genéticamente.

${ }^{7}$ En particular, resultan relevantes los siguientes instrumentos y foros internacionales: el TRIPS en el contexto de la Organización Mundial de Comercio, OMC (Trade Related Intellectual Property Rights Agreement o Acuerdo sobre los Derechos de Propiedad Intelectual relacionados con el Comercio); algunos de los tratados y negociaciones que administra la Organización Mundial de la Propiedad Intelectual (OMPI), por ejemplo, la Convención de París para la Protección de la Propiedad Industrial de 1883, las negociaciones en curso en torno a un Tratado sobre Derecho Sustantivo de Patentes y el trabajo que desarrolla la Comisión Intergubernamental sobre Conocimientos Tradicionales y Folklore; y las convenciones internacionales en materia de derechos de obtentores de variedades vegetales adoptadas en el contexto de la UPOV (Unión Internacional para la Protección de Obtenciones Vegetales), específicamente las de 1978 y 1991. 
cia. Sin embargo, a pesar de las aparentes similitudes con la explotación de recursos tales como el petróleo o los minerales, en este caso nos encontramos ante una situación completamente novedosa. Esto, porque se trata de recursos vivos cuya eventual utilización depende fundamentalmente de la tecnología apropiada. Con lo cual se configura en este caso una situación de acceso con características muy específicas, en que el escenario tradicional del país desarrollado que, gracias a su mayor capacidad tecnológica, puede explotar los recursos pertenecientes a países menos desarrollados y apropiarse de la mayor parte de los beneficios derivados de su utilización, adquiere una complejidad tal, que puede resultar contraproducente para un país proveedor de recursos genéticos abordar la regulación de su acceso desde un punto de vista similar al de los demás recursos naturales.

Es decir, la idea tradicionalmente presente en la regulación interna del acceso a los recursos naturales, que sostiene que un país tendrá una mejor posición negociadora si cuenta con una normativa de acceso esencialmente restrictiva, es probablemente inadecuada para abordar la utilización de los recursos genéticos de un modo que resulte efectivo y eficiente para los intereses del país proveedor. En efecto, es muy poco probable que dicha utilización incida de manera significativa en las ganancias de un país proveedor de recursos. El material genético suele tener una amplia distribución geográfica, es muy fácil transportarlo y, gracias al acelerado avance de la tecnología, es cada vez más simple obtener y reproducir la información que le da valor. Además, en la actualidad las ventajas competitivas en el mercado de la oferta de recursos genéticos están directamente relacionadas a la posibilidad de contar con un producto que tenga mayor valor agregado, con lo cual el valor comercial de la materia prima es cada vez menor.

Sin embargo, si un país proveedor de recursos genéticos logra estructurar una fórmula normativa de acceso y distribución de los beneficios que sea correcta, los resultados pueden ser muy valiosos, tanto desde la perspectiva del desarrollo tecnológico nacional como desde la perspectiva de la conservación y utilización sostenible de los recursos de la diversidad biológica.

Es así como desde hace algunos años se realizan esfuerzos con el objeto de integrar en la regulación del acceso a los recursos genéticos los elementos necesarios para incentivar su utilización y desarrollar tecnologías, y a la vez promover su conservación.

La finalidad de este trabajo es analizar cómo dichos esfuerzos de integración han evolucionado a nivel internacional. Antes de entrar a dicho análisis, y con el objeto de explicar la necesidad de la integración entre un sistema de acceso a los recursos genéticos y un sistema relativo a la propiedad intelectual, en la primera parte se explican los principales aspectos en que ambos regímenes jurídicos pueden entrar en conflicto. A continuación, en una segunda parte, se realiza un análisis de las principales iniciativas en curso en el ámbito de la coordinación e integración de los diversos instrumentos internacionales relevantes. Finalmente, concluiremos este trabajo con algunas ideas en torno a los desafíos que enfrenta Chile en este proceso. 


\section{LOS POSIBLES CONFLICTOS ENTRE EL RÉGIMEN JURÍDICO DE LA PROPIEDAD INTELECTUAL Y EL DE LA CONSERVACIÓN Y USO SUSTENTABLE DE LA BIODIVERSIDAD}

El aspecto de fondo del debate en esta materia dice relación con si los derechos de propiedad intelectual (DPI) sobre las innovaciones derivadas de recursos genéticos y de los conocimientos tradicionales asociados a éstos pueden llegar a constituir incentivos para la conservación, protección y utilización sustentable de dichos recursos y conocimientos (y, en general, para el desarrollo de los países proveedores de tales recursos) o, más simplemente, si son compatibles con dichos objetivos. ${ }^{8}$ Existen diversas posiciones en torno a este debate, siendo los siguientes tres enfoques los que han predominado. ${ }^{9}$ En primer lugar, algunos países como la India y el Grupo de los Países Africanos sostienen que existe un conflicto inherente entre la CDB y el TRIPS, y que este último debe ser modificado con el objeto de eliminar dicho conflicto. ${ }^{10}$ Otros países, como EE.UU., sostienen que se trata de tratados independientes y con objetivos distintos y que la concesión de DPI sobre este tipo de invenciones no impide el cumplimiento de los objetivos ambientales, cuestión que se debe lograr a través de la adopción de medidas legislativas nacionales. Por último, están aquellos países que sostienen que existen posibles fuentes de conflictos entre ambos regímenes dependiendo de la forma en que se los implemente, por lo que se requiere de cooperación internacional para lograr una aplicación complementaria de estos instrumentos. Esta última es, probablemente, la posición mayoritaria y fundamenta los esfuerzos de coordinación e integración en curso a nivel internacional.

Cualquiera sea el enfoque utilizado, se han identificado posibles focos de conflicto entre ambos regímenes, los que se deben tener en cuenta al momento de adoptar una posición al respecto. Estos se refieren básicamente a los siguientes cuatro aspectos: la patentabilidad de formas de vida; la distribución equitativa de los beneficios prove-

${ }^{8}$ Al respecto ver: Dutfield, G.,"Sharing the Benefits of Biodiversity: Access Regime and Intellectual Property Rights”, Science, Technology and Development Discussion Paper N ${ }^{\circ}$ 6, Center for International Development and Belfer Center for Science and International Affairs, Harvard University, Cambridge, MA, USA, 1999; Dutfield, G., "Intellectual Property Rights, Trade and Biodiversity", Earthscan Publications Ltd, London, 2000; y Commission on Intellectual Property Rights (CIPR), "Integrating Intellectual Property Rights and Development Policy”, London, 2002.

${ }^{9}$ Estos enfoques han sido planteados específicamente en el debate sobre la relación de la CDB con el TRIPS, pero pueden ser extrapolables a la relación más general entre los diversos instrumentos a los que nos referimos en este trabajo (Council for TRIPS, "The Relationship Between the Trips Agreement and the Convention on Biological Diversity. Summary of Issues Raised and Points Made. Note by The Secretariat", 8 agosto 2002, pp. 2-4. WTO Document IP/C/W/368).

${ }^{10} \mathrm{E}$ conflicto de fondo estaría en que el TRIPS permite la apropiación privada de los recursos genéticos, lo que resultaría inconsistente con los derechos soberanos de los países sobre dichos recursos, según lo establece la CDB. Sin embargo, se ha respondido que obtener un DPI sobre material genético no equivale a obtener la propiedad del gen y que al existir intervención humana, aunque sea sólo para aislar un gen, hay lugar para una "invención” que se puede proteger por los DPI, a diferencia de los "descubrimientos", que no son objeto de DPI. 
nientes de la utilización de los recursos genéticos; la protección de los conocimientos tradicionales de las comunidades indígenas, y la transferencia de tecnologías. ${ }^{11}$

\section{La patentabilidad de la vida}

Las patentes han sido los DPI más discutidos en torno a su vinculación con la protección de la biodiversidad. Uno de los aspectos más controvertidos dentro de las negociaciones del TRIPS fue la posibilidad de las Partes de efectuar exclusiones genéricas de la patentabilidad y de establecer excepciones a los derechos conferidos por una patente. En este contexto, un tema muy discutido fue la patentabilidad de los organismos vivos, específicamente las plantas y los animales. La disposición relevante del TRIPS en esta materia es el artículo 27.3.b) que dispone:

Los Miembros podrán excluir asimismo de la patentabilidad: b) las plantas y los animales excepto los microorganismos, y los procedimientos esencialmente biológicos para la producción de plantas o animales, que no sean procedimientos no biológicos o microbiológicos. Sin embargo, los Miembros otorgarán protección a todas las obtenciones vegetales mediante patentes, mediante un sistema eficaz sui generis o mediante una combinación de aquéllas y éste.

Esta disposición refleja la discusión en torno a la conveniencia de otorgar patentes sobre invenciones relacionadas con plantas y animales. La redacción del artículo, sin embargo, es tan confusa como la discusión. En todo caso, de esta norma se desprende que las partes pueden excluir de la patentabilidad a las plantas y animales, como "productos". Y, en relación con los "procesos", también se pueden excluir los esencialmente biológicos para la producción de plantas y animales. Por otro lado, las patentes deben estar disponibles para los microorganismos como "productos" y para los "procesos" no biológicos o microbiológicos para producir plantas o animales. ${ }^{12}$ Por último, las Partes se obligan a proteger las obtenciones de variedades vegetales ${ }^{13}$ ya sea mediante un sistema de patentes, un sistema sui géneris (tal como el sistema de los derechos de obtentores establecido por UPOV) o una combinación de ambos sistemas. ${ }^{14}$ Esta norma especial para las variedades vegetales deriva de la preocupación de algunos en torno a que el

${ }^{11}$ Mann, H. \& Porter, S., "The State of Trade and Environment Law, 2003. Implications for Doha and Beyond", IIISD y CIEL, p. 39.

12 Dutfield, G., "Intellectual Property Rights...", p. 21.

${ }^{13}$ Se entiende por "variedad vegetal" a un conjunto de plantas de un solo taxón botánico del rango más bajo conocido que, con independencia de si responde o no plenamente a las condiciones para la concesión de un derecho de obtentor, pueda definirse por la expresión de los caracteres resultantes de un cierto genotipo o de una cierta combinación de genotipo; distinguirse de cualquier otro conjunto de plantas por la expresión de uno de dichos caracteres por lo menos; considerarse como una unidad, habida cuenta de su aptitud a propagarse sin alteración (artículo 1(vi) de UPOV 1991).

${ }^{14}$ El problema que aquí se plantea es cómo distinguir una planta de una variedad vegetal. Este problema adquiere gran relevancia cuando hablamos de las "plantas transgénicas”, es decir, aquellas generadas por la aplicación de la biotecnología moderna. 
TRIPS no plantea un balance adecuado entre los titulares de los DPI y otros intereses involucrados, tales como las comunidades rurales cuyos conocimientos tradicionales han generado valiosas variedades vegetales. ${ }^{15}$

Según algunos, incluir la posibilidad de patentar formas de vida favorecería la inversión privada en esta área, lo que contribuiría a solucionar grandes problemas agrícolas, de salud, nutricionales y del medio ambiente. Otros, en cambio, consideran que dicha posibilidad da lugar a diversas preocupaciones relacionadas con el desarrollo, la seguridad alimentaria, el medio ambiente, la cultura y la ética. ${ }^{16}$

A raíz de estas divergencias de opinión es que se acordó, al momento de adoptar el TRIPS, revisar su artículo 27.3.b), ${ }^{17}$ trabajo que se inició en 1999 y que hasta la fecha no ha concluido. Resulta relevante resaltar que en el 2001 la Declaración Ministerial de Doha (de la OMC) amplió esta discusión en curso con el objeto que se incluyera en general la relación del TRIPS con la CDB y la protección de los conocimientos tradicionales. $^{18}$

\section{La distribución equitativa de los beneficios provenientes de la utilización de los recursos genéticos}

El artículo 15 de la CDB reconoce la soberanía de los Estados sobre los recursos naturales, otorgándoles la facultad de regular el acceso a los recursos genéticos y sometiendo las condiciones de acceso a la legislación nacional. A su vez, establece que las Partes deberán facilitar las condiciones de acceso a otras Partes, para utilizaciones ambientalmente adecuadas, sin imponer condiciones contrarias a la misma Convención. Por último, el acceso estará sometido tanto al "consentimiento informado previo" como al establecimiento de la "distribución justa y equitativa" de los resultados de las actividades de investigación y desarrollo, y de los beneficios derivados de la utilización comercial y de otra índole, con la Parte que proporciona los recursos. Esta participación se llevará a cabo en "condiciones mutuamente acordadas".

El problema que se plantea con los instrumentos de propiedad intelectual consiste en que éstos autorizan el otorgamiento de patentes para invenciones que utilicen recur-

${ }^{15}$ Council for TRIPS, "Review of the Provisions of Article 27.3.b). Summary of Issues Raised and Points Made. Note by the Secretariat", 8 de agosto de 2002 (WTO Document IP/C/W/369).

${ }^{16}$ Ibid.

${ }^{17}$ La frase final de este artículo señala: Las disposiciones del presente apartado serán objeto de examen cuatro años después de la entrada en vigor del Acuerdo sobre la OMC.

18 Párrafo 19 de la Declaración de Doha: Encomendamos al Consejo de los ADPIC que, al llevar adelante su programa de trabajo, incluso en el marco del examen previsto en el párrafo 3 b) del artículo 27, del examen de la aplicación del Acuerdo sobre los ADPIC previsto en el párrafo 1 del artículo 71 y de la labor prevista en cumplimiento del párrafo 12 de la presente Declaración, examine, entre otras cosas, la relación entre el Acuerdo sobre los ADPIC y el Convenio sobre la Diversidad Biológica, la protección de los conocimientos tradicionales y el folclore, y otros nuevos acontecimientos pertinentes señalados por los Miembros de conformidad con el párrafo 1 del artículo 71. Al realizar esta labor, el Consejo de los ADPIC se regirá por los objetivos y principios enunciados en los artículos 7 y 8 del Acuerdo sobre los ADPIC y tendrá plenamente en cuenta la dimensión de desarrollo. 
sos genéticos sin exigir el cumplimiento de los requisitos que impone la CDB, esto es, el consentimiento informado previo y la distribución de los beneficios. ${ }^{19}$ Es así como, según veremos en la segunda parte de este trabajo, se ha sugerido una modificación del régimen de propiedad intelectual con el objeto de incorporar, a las solicitudes de patentes, la exigencia de revelar el origen de los recursos genéticos y de los conocimientos tradicionales utilizados en la invención correspondiente, y acreditar el consentimiento informado previo del país de origen. ${ }^{20}$

\section{La protección de los conocimientos tradicionales}

El artículo 8(j) de la CDB se refiere a este tema, señalando que cada Parte deberá respetar, preservar y mantener los conocimientos, las innovaciones y las prácticas de las comunidades indígenas y locales que entrañen estilos tradicionales de vida pertinentes para la conservación y la utilización sostenible de la diversidad biológica. De igual manera deberá promover la más amplia aplicación de esos conocimientos, innovaciones y prácticas con la aprobación y participación de los poseedores de los mismos y fomentar que los beneficios derivados de la utilización de esos conocimientos, innovaciones y prácticas se compartan equitativamente.

De esta manera, la CDB reconoce que los conocimientos y prácticas de las comunidades indígenas y locales son importantes para el cumplimiento de sus objetivos. A su vez, la $\mathrm{CDB}$ reconoce que estos conocimientos no son estáticos, sino que por el contrario son dinámicos, y es por eso que habla de estos conocimientos y prácticas como “innovaciones”, además de referirse a su contenido tradicional.

Esta importancia se debe a que dichos conocimientos y prácticas contienen experiencias y visiones directas de los ecosistemas y sus recursos biológicos, que pueden y deben constituir una base para su manejo sustentable, conservación e investigación científica. Por otro lado, la importancia de proteger estos conocimientos dice relación también con el derecho a mantener la integridad cultural de un pueblo, derecho reconocido por el derecho internacional de los derechos humanos. ${ }^{21}$ Por último, estos conocimientos y prácticas son potencialmente valiosos como fuentes para el desarrollo de productos farmacéuticos, agrícolas, industriales y alimenticios. ${ }^{22}$

En relación a esta materia y su vínculo con los DPI existen opiniones divergentes. En efecto, algunos sostienen que los DPI existentes pueden crear incentivos directos

${ }^{19}$ Esta situación ha permitido la apropiación indebida de recursos genéticos y conocimientos asociados, situación conocida como "biopiratería". Ver infra en la sección III de este trabajo algunos ejemplos de biopiratería relevantes para Chile.

${ }^{20}$ Council for TRIPS, "The Relationship Between the TRIPS Agreement and the Convention on Biological Diversity”, pp. 6-9.

${ }^{21}$ James Anaya reconoce este derecho como parte de las normas internacionales consuetudinarias concernientes a los pueblos indígenas ("Los derechos de los pueblos indígenas", en La Protección Internacional de los Derechos Humanos en los Albores del S. XXI, F. Gómez ed., U. Deusto, Bilbao, 2003).

${ }^{22}$ Este factor tiene directa relación con los DPI, debido a que los conocimientos tradicionales han sido usados en muchas industrias como un punto de partida para el desarrollo de nuevos productos. 
o indirectos para una mayor inversión de las comunidades indígenas y locales en la mantención de sus conocimientos y prácticas, al menos si se combinan con acuerdos de distribución de los beneficios respectivos. ${ }^{23}$ Por otro lado, hay quienes sostienen que los DPI son insuficientes para la protección de los derechos de propiedad cultural de los pueblos indígenas, debido en gran parte a los requisitos de los DPI, que no son concordantes con las características de los conocimientos indígenas. ${ }^{24}$ Por ejemplo, las patentes de invención se basan en derechos de propiedad individual, mientras estos conocimientos son generalmente colectivos e intergeneracionales; por otro lado, también exigen que la materia patentable sea "nueva" cuando los conocimientos indígenas son, por definición, parte del conocimiento popular. También se sostiene que los DPI tienden a mercantilizar estos conocimientos infringiendo valores y costumbres indígenas y locales, tales como la libre disponibilidad e intercambio de conocimientos y prácticas entre distintos grupos. ${ }^{25}$ Por último, el conocimiento tradicional no explica el proceso por el cual se logra un determinado efecto, sino que, por el contrario, muchas veces se lo atribuye a poderes o entes sobrenaturales, lo que redundaría en la imposibilidad de patentarlo. Estas características de los DPI en vez de proteger los conocimientos indígenas los paralizarían e impedirían su evolución y desarrollo.

En cuanto a los problemas específicos de la propiedad intelectual en relación con la protección de estos conocimientos dentro de un régimen de acceso se han mencionado dos puntos de conflicto: ${ }^{26}$ que los instrumentos que regulan los DPI autorizan la concesión de patentes sobre invenciones que han utilizado estos conocimientos sin exigir el consentimiento informado previo de la comunidad indígena o tradicional respectiva, ${ }^{27}$ y que tampoco requieren de un acuerdo sobre distribución de los beneficios provenientes de dicha utilización.

\section{La transferencia de tecnología}

El artículo 16.1 de la CDB señala que se debe asegurar y facilitar el acceso a las tecnologías (incluyendo la biotecnología) pertinentes para la conservación y utilización sostenible de la diversidad biológica o que utilicen recursos genéticos y no causen daños significativos al medio ambiente, así como la transferencia de esas tecnologías. Este acceso a la tecnología ha de hacerse en las condiciones más justas y en los términos más favorables tratándose de países en desarrollo.

${ }^{23}$ Downes, D., "How Intellectual Property Could Be a Tool to Protect Traditional Knowledge", en 25 Columbia Journal of Environmental Law, 2000, p. 257.

${ }^{24}$ Ibid.

25 Ibid.

${ }^{26}$ Council for TRIPS, "The Protection of Traditional Knowledge and Folklore. Summary of Issues Raised and Points Made. Note by the Secretariat", 8 de agosto de 2002, pp. 1-11 (WTO Document $\mathrm{IP} / \mathrm{C} / \mathrm{W} / 370)$.

${ }^{27}$ En todo caso, es poco probable que se pueda otorgar el consentimiento informado previo para el acceso a un conocimiento respecto del cual no se sabe su contenido o real significado. 
El debate en este aspecto se refiere a si los DPI, específicamente las patentes, generan incentivos para la difusión o transferencia de tecnologías a los países en desarrollo, ya sea de aquellas tecnologías relevantes para la conservación y uso sustentable de los componentes de la biodiversidad como de las biotecnologías que utilizan recursos genéticos.

Los DPI constituyen incentivos para la innovación, esto es, para la generación de nuevas tecnologías. Sin embargo, es más discutible si pueden constituir incentivos para la difusión y transferencia de tecnologías. A pesar de ello, el propio artículo 7 del TRIPS dispone que la protección de los DPI no sólo deberá contribuir a la innovación tecnológica sino que también a la transferencia y difusión de la tecnología. Incluso en el artículo 8 sobre Principios del TRIPS se establece la posibilidad de adoptar medidas apropiadas para evitar prácticas que perjudiquen dicha transferencia. Estas disposiciones tienen su fundamento en que los titulares de los DPI deberían estar dispuestos a transferir tecnologías puesto que el TRIPS garantiza que el país receptor cuente con un sistema de DPI que otorgue protección efectiva a sus derechos. A su vez, el TRIPS podría incentivar la transferencia de tecnologías a través de otras dos disposiciones específicas: la que permite utilizar la materia de una patente sin autorización de su titular (o "licencias obligatorias" del artículo 31) y la que, como vimos, permite excluir ciertas materias de la patentabilidad (artículo 27.3.b). Sin embargo, estas normas establecen una serie de requisitos y condiciones para su implementación que la hacen más difícil, y no constituyen necesariamente una obligación positiva de transferir tecnología a los países en desarrollo.

Desde el punto de vista de la CDB (y de los tratados ambientales en general) la transferencia de tecnologías es considerada como un método fundamental para lograr sus objetivos. En el caso específico de la CDB se trata, en particular, de lograr la participación justa y equitativa en los beneficios que se deriven de la utilización de los recursos genéticos. En efecto, el artículo 1 señala que dicho objetivo se logrará, entre otras cosas, mediante la transferencia apropiada de las tecnologías pertinentes, teniendo en cuenta todos los derechos sobre esas tecnologías. Es posible concluir que la referencia a los "derechos" incluye a los DPI correspondientes, por lo que la CDB no impondría obligaciones contradictorias a la protección de estos derechos, sino que por el contrario los DPI constituirían un aspecto relevante de la transferencia de tecnología perseguida por la Convención. ${ }^{28}$

Hemos visto, entonces, que existen diversas áreas de posibles conflictos entre un régimen de acceso a los recursos genéticos y un régimen de protección de la propiedad intelectual. La apuesta de buena parte de la comunidad internacional preocupada de la conservación y uso sustentable de la biodiversidad sostiene que dichos conflictos se pueden resolver en la medida que se busque una implementación coordinada e integrada de ambos sistemas.

${ }^{28}$ Kruger, M., "Harmonizing TRIPS and the CDB: A Proposal from India", en 10 Minnesota Journal Global Trade, 2001, p. 169. 


\section{INICIATIVAS DESTINADAS A UNA APLICACIÓN INTEGRADA} DE LOS INSTRUMENTOS INTERNACIONALES RELEVANTES PARA UN SISTEMA DE ACCESO A LOS RECURSOS GENÉTICOS

Como ya señalamos, el escenario internacional en materia de recursos genéticos está compuesto por diversos instrumentos y organizaciones internacionales que, por una parte, protegen y regulan la conservación y el acceso a los recursos genéticos y, por la otra, establecen el régimen aplicable para la propiedad intelectual asociada a las tecnologías que utilizan dichos recursos. Tradicionalmente tales instrumentos y organizaciones han funcionado de manera independiente y muchas veces incluso contrapuesta. Sin embargo, diversos esfuerzos por integrar ambos tipos de objetivos tienen lugar en la actualidad a través de las negociaciones correspondientes en los foros que representan la CDB, la FAO, la OMC, la OMPI y UPOV. Pasaremos a revisar el contenido de las principales iniciativas desarrolladas.

1. Iniciativas de integración en el contexto de la CDB. La búsqueda del establecimiento de un régimen internacional coherente para el acceso a los recursos genéticos y la distribución de sus beneficios

No hay duda que el foro internacional más relevante en materia de acceso a recursos genéticos es el que proporciona la CDB. Es así como, en la actualidad, la comunidad internacional se encuentra negociando en el contexto de este tratado el establecimiento de un "régimen internacional para promover y salvaguardar la distribución equitativa de los beneficios provenientes de la utilización de los recursos genéticos", según los términos utilizados por el Plan de Implementación de los resultados de la "Conferencia de Johannesburgo para el Desarrollo Sustentable”, de agosto de 2002. ${ }^{29}$ El Grupo de Trabajo de la CDB sobre Acceso y Distribución de los Beneficios ${ }^{30}$ decidió iniciar dichas negociaciones invitando a todos los actores relevantes a que presenten sus comentarios y propuestas en torno al "ámbito, naturaleza, potenciales objetivos y elementos de un régimen internacional en esta materia". ${ }^{31}$ Dicho proceso es reciente, sin embargo se

${ }^{29}$ Párrafo 44 (o) del Plan, que se basó en una iniciativa del grupo de países conocido como Países Megadiversos Afines (Brasil, China, Colombia, Costa Rica, Ecuador, India, Indonesia, Kenya, México, Perú, Sudáfrica y Venezuela). La Asamblea General de las NU, en su sesión No 57, a través de la Resolución 57/260, reafirmó el compromiso de la Conferencia Mundial para el Desarrollo Sustentable de negociar un régimen internacional para la distribución de los beneficios, e invitó a la CDB a tomar las medidas apropiadas con dicho propósito (Earth Negotiations Bulletin, Vol. 09 No. 268, Monday, 8 December 2003, publicado por el International Institute for Sustainable Development, IISD).

${ }^{30}$ La Séptima Conferencia de las Partes del CDB decide otorgar un mandato a este Grupo de Trabajo para que elabore y negocie un régimen internacional con el objetivo de adoptar un instrumento o instrumentos que efectivamente implementen las disposiciones relevantes de la CDB, considerando los demás instrumentos y procesos existentes (Decisión VII/19 D, párrafo 1, febrero 2004).

${ }^{31}$ Report of the Ad hoc Open Ended WK on ABS on the work of its Third Meeting (UNEP/CBD/ WG-ABS/3/7, 3 March 2005). 
beneficiará de un contexto internacional en el que ya existen diversas negociaciones en curso con el objeto de lograr una implementación coordinada y complementaria de los tratados en juego.

Los elementos que debieran integrar dicho régimen internacional se pueden entonces deducir de las negociaciones existentes, impulsadas en gran parte por la CDB que, desde un comienzo, ha desarrollado iniciativas de coordinación con organizaciones como la FAO, la OMC, la OMPI y UPOV. ${ }^{32}$

Por ejemplo, en relación con la FAO, la CDB ha reconocido la importancia del TI/RFAA para la conservación y el uso sustentable de la agrobiodiversidad, para facilitar el acceso a los recursos fitogenéticos y para la distribución equitativa de los beneficios provenientes de su utilización, y ha establecido una cooperación permanente entre ambos tratados a través de sus respectivas Secretarías. ${ }^{33}$ Los aspectos fundamentales sobre los que recae dicha cooperación y coordinación se refieren al "Sistema Multilateral de Acceso y Distribución de los Beneficios" establecido por el TI/RFAA, ${ }^{34}$ a los "derechos de los agricultores", ${ }^{35}$ y a la situación de las "colecciones ex situ" de recursos genéticos, ${ }^{36}$ todos los cuales debieran ser parte de un régimen jurídico internacional en materia de acceso.

Por otro lado, la CDB también ha reconocido la existencia de vínculos cercanos entre sus disposiciones en materia de recursos genéticos y las normas internacionales en materia de derechos de propiedad intelectual. ${ }^{37}$ Uno de los aspectos principales que es

${ }^{32}$ En efecto, la CDB ha reconocido consistentemente la importancia de la cooperación y las sinergias con otras convenciones y organizaciones, y ha enfatizado la necesidad de implementar la CDB y otros instrumentos internacionales de manera que se apoyen mutuamente (Secretariat of CBD, "Handbook of the Convention on Biological Diversity, including its Cartagena Protocol on Biosafety", $3^{\text {rd }}$ Edition, Earthscan Publications, 2005, p. 365).

33 Decisión VI/6 (Abril 2002).

${ }^{34}$ El TI/RFAA crea un cuerpo de normas de acceso y distribución de los beneficios distinto al establecido por la CDB. En efecto, crea un sistema multilateral de acceso a los recursos fitogenéticos bajo el cual se determinan las condiciones y requisitos para que las partes accedan, en un comienzo, a 65 tipos diferentes de recursos genéticos relevantes para la alimentación y la agricultura. La CDB, en cambio, crea un sistema bilateral de acceso que consiste en que el país proveedor de los recursos debe autorizar el acceso a sus recursos genéticos a quien quiera utilizarlos, y negociar un acuerdo bilateral de distribución de beneficios.

${ }^{35}$ El concepto de los "derechos de los agricultores" nace en el contexto del Compromiso Internacional de 1983 de la FAO, y tiene por objeto compensar a los pequeños agricultores por sus esfuerzos en la conservación y desarrollo de los recursos fitogenéticos. El TI/RFAA también los incluye y establece que se deben proteger a nivel nacional, ya sea a través de la protección de los conocimientos tradicionales o la participación de las comunidades rurales y pueblos indígenas en los beneficios derivados del uso de los recursos.

${ }^{36}$ El artículo 15.3 de la CDB excluye de su sistema de acceso a aquellos recursos que hayan sido recolectados con anterioridad a la entrada en vigencia de la CDB. De esta manera, el acceso a las colecciones ex situ preexistentes de recursos genéticos no se someten a sus normas. Algunas de estas colecciones se rigen por el Sistema Global de la FAO sobre Recursos Fitogenéticos y por el TI/RFAA. En todo caso, la CDB ha comenzado a preguntarse acerca del tratamiento que las otras colecciones ex situ, aquellas que se encuentran fuera del sistema de la FAO, deben recibir. Para ello se ha iniciado un ejercicio de reunión de información (Decisión VI/24 D, párrafo 8).

${ }^{37}$ En efecto, el Artículo 16.5 de la CDB reconoce que los DPI tienen una directa relación con el acceso a los recursos genéticos y la distribución de los beneficios. Establece: Las Partes Contratantes, reconociendo que 
actualmente objeto de negociación dice relación con los requisitos relativos a "la revelación del origen" de los recursos genéticos y los conocimientos tradicionales asociados a éstos, cuando se solicita una patente sobre invenciones que utilicen dichos recursos y conocimientos. $\mathrm{La} \mathrm{CDB}$ ha tratado este asunto invitando a las Partes a promover, en las solicitudes de dichas patentes, la revelación del país de origen de los recursos y de los conocimientos tradicionales asociados a éstos, como una forma de garantizar el cumplimiento de los requisitos del "consentimiento informado previo" y de los "términos mutuamente acordados" que exige para otorgar el acceso. ${ }^{38}$

Por otra parte, también se negocian en la actualidad las condiciones para el "acceso y transferencias de tecnologías” según lo establecido por el artículo 16 de la CDB. Como ya vimos, este artículo ha suscitado cuestionamientos en torno a la compatibilidad entre este instrumento y aquellos relacionados con la propiedad intelectual. Sin embargo, al menos la Secretaría de la CDB ha manifestado, en relación con el TRIPS, que ambos acuerdos admiten un margen de flexibilidad en su implementación nacional, lo que permite concluir que existe el potencial para una implementación sinérgica y complementaria. ${ }^{39}$ Es así como durante la última Conferencia de las Partes de la CDB se adoptó un programa de trabajo en transferencia de tecnologías y cooperación científica y tecnológica ${ }^{40}$ que requerirá de parte de la CDB, OMPI y otras organizaciones internacionales analizar el rol de los DPI en la transferencia de tecnología con el objeto de explorar opciones para superar las barreras existentes y aumentar las sinergias posibles entre los tratados aplicables a los recursos genéticos. ${ }^{41}$

Por último, actualmente también se discute el uso de los DPI en relación con la “protección de los conocimientos tradicionales". La CDB decidió mandatar a su Grupo de Trabajo en materia de Conocimientos Tradicionales para que, en colaboración con las organizaciones internacionales relevantes, desarrolle los elementos de un sistema sui generis para la protección del conocimiento tradicional y explore las condiciones bajo las cuales los DPI existentes pueden contribuir a lograr los objetivos del artículo 8 (j) de la $\mathrm{CDB}$, todo con el objeto de elaborar recomendaciones para un régimen internacional de acceso. ${ }^{42}$

las patentes y otros derechos de propiedad intelectual pueden influir en la aplicación del presente Convenio, cooperarán a este respecto de conformidad con la legislación nacional y el derecho internacional para velar porque esos derechos apoyen y no se opongan a los objetivos del presente Convenio.

38 Decisión VI/24 C, párrafos 1 y 2. A su vez, la CDB ha invitado a la OMPI a preparar un estudio relacionado con los requisitos de "revelación del origen" en materia de patentes (Decisión VI/24 C, párrafo 4).

39 UNEP/CBD/COP/3/23, "The Convention on Biological Diversity and the Agreement on Traderelated Aspects of Intellectual Property Rights (TRIPS): Relationships and synergies", 5 October 1996 (paragraph 35).

${ }^{40}$ Decisión VII/29.

${ }^{41}$ Decisión VII/29, Anexo, Elemento 3 del Programa.

42 Decisión VII/16,VI.H, párrafo 8; y South Centre \& CIEL, "IP Quarterly Update: Third Quarter 2004”, p. 18. 


\section{Iniciativas de integración en el contexto de los instrumentos de la propiedad intelectual,} ¿un objetivo realista?

Las iniciativas que tienen lugar en el contexto del TRIPS/OMC, OMPI y UPOV se refieren básicamente a los mismos elementos que mencionamos en la sección anterior. Así, por ejemplo, las negociaciones que han tenido lugar en el Consejo del TRIPS ${ }^{43} \mathrm{de}$ la OMC se han ocupado de los requisitos para la patentabilidad del material genético, de la posible protección de los conocimientos tradicionales a través de los DPI y de los problemas que estos derechos pueden generar respecto a la transferencia de tecnologías. UPOV, por su parte, ha manifestado que la CDB y los instrumentos internacionales que tratan la propiedad intelectual deben apoyarse mutuamente y ha indicado cuáles son los elementos que, desde la perspectiva de los derechos del obtentor, deben integrar un régimen internacional para el acceso a los recursos genéticos. ${ }^{44}$ Por último, la OMPI ha trabajado activamente en este tema desde el año 2000, con la creación de su Comité Intergubernamental sobre Propiedad Intelectual, Recursos Genéticos y Conocimientos Tradicionales y Folklore, que tiene por objeto la definición de los criterios y elementos necesarios para compatibilizar un régimen de acceso con un sistema de protección de los DPI. ${ }^{45}$ Veremos a continuación los contenidos principales de estas iniciativas.

Como ya indicamos, el Consejo del TRIPS ha abordado los principales elementos relevantes para un régimen jurídico en materia de recursos genéticos. En efecto, con respecto a la "patentabilidad del material genético", el Consejo se encuentra trabajando en la revisión del artículo 27.3.b). Se han sugerido diversas posibilidades para su revisión ${ }^{46}$ que van desde considerar que las excepciones a la patentabilidad establecidas por dicha disposición son innecesarias (por lo que se debe extender la patentabilidad a las plantas y animales) hasta que se debe modificar el artículo prohibiendo la patentabilidad de todas las formas de vida (plantas, animales, microorganismos y cualquier otro organismo vivo, incluyendo sus partes, como los genes) ${ }^{47}$ En relación con el sistema sui generis de

${ }^{43}$ De acuerdo con el Artículo 68 del TRIPS, este Consejo es el encargado de supervisar la aplicación del Acuerdo y, en particular, el cumplimiento por los Miembros de las obligaciones que les incumben en virtud del mismo. Este organismo ofrece a los miembros la oportunidad de celebrar consultas sobre cuestiones referentes a los aspectos de los derechos de propiedad intelectual relacionados con el comercio.

${ }^{44}$ UPOV, "Access to Genetic Resources and Benefit-Sharing. Reply of UPOV to the Notification of June 26, 2003, from the Executive Secretary of the Convention on Biological Diversity (CBD)", adoptado por el Consejo de UPOV en su sesión ordinaria $\mathrm{N}^{\circ} 37$ de 23 de octubre de 2003, p. 2.

${ }^{45}$ Por otra parte, también han sido relevantes en el contexto de la OMPI las negociaciones que se desarrollan para adoptar un tratado sobre derecho sustantivo de patentes. Estas negociaciones se desarrollan en el Comité Permanente sobre el Derecho de Patentes cuyo mayor logro ha sido la adopción, en junio de 2000 , de un Tratado sobre el Derecho de Patentes, el que entró en vigencia en abril de 2005. Sin embargo, este tratado armoniza sólo los aspectos formales y de procedimiento respecto a las solicitudes de patentes. Es por ello que, posteriormente, el Comité decide iniciar negociaciones tendientes a una armonización sustantiva sobre el derecho de patentes.

${ }^{46}$ Council for TRIPS, "Review Of The Provisions Of Article 27.3(B)...".

47 Posiciones intermedias sostienen que debiera mantenerse el artículo como está o simplemente modificarlo para aclarar ciertos conceptos, como el de microorganismo. 
protección para las variedades vegetales se ha sugerido aclarar el significado de la expresión "sistema eficaz sui géneris". Algunos consideran que se debiera incorporar una referencia expresa a UPOV, ${ }^{48}$ mientras otros creen que la flexibilidad se debe mantener con el objeto de autorizar a los miembros a adoptar otros sistemas más consistentes con la CDB o el TI/RFAA.

En cuanto al "consentimiento informado previo y distribución equitativa de los beneficios”, las negociaciones surgen a raíz de la ausencia de estos requisitos en el TRIPS y demás instrumentos de la propiedad intelectual para otorgar patentes sobre material genético. Se ha sugerido que debieran modificarse de manera de incorporar el requisito de la revelación del origen de la fuente del material genético utilizado y de cualquier conocimiento tradicional asociado que se haya utilizado en la invención; la exigencia de probar el consentimiento informado previo de la autoridad competente del país de origen; y la distribución justa y equitativa de los beneficios. Otros, en cambio, señalan que dicha modificación no es necesaria puesto que los requisitos que impone la CDB deben implementarse a través de los correspondientes contratos a nivel nacional y no a través del TRIPS. Sin embargo, algunos países en desarrollo critican este enfoque puesto que basarse en la celebración de contratos a nivel nacional no garantizaría la regulación de aquellas situaciones en que los proyectos de bioprospección tienen lugar sin la debida autorización del país proveedor, y por lo tanto, sin la celebración de contrato alguno. La discusión continúa hasta ahora, manteniendo los países en desarrollo la demanda de introducir al TRIPS los requisitos de revelar el origen, y probar la distribución de los beneficios. En particular, se han presentado propuestas para determinar cómo distribuir los beneficios, cuándo exigir prueba de cumplimiento de estos requisitos, qué pasaría en el caso de ausencia de un régimen jurídico nacional de acceso y los efectos en caso de incumplimiento. ${ }^{49}$ EE.UU., Canadá, Japón y la UE mantienen su oposición a la introducción al TRIPS de los requisitos de revelación del origen. ${ }^{50}$

También se han discutido las implicancias de los DPI respecto del acceso y "transferencia de tecnologías". 51 Una posición sostiene que los DPI sobre formas de vida y material genético pueden impedir el acceso y aumentar el costo de la tecnología en esta área a través de los derechos exclusivos que se otorga a los titulares de los mismos para impedir a los demás el uso de la tecnología protegida. Otros, en cambio, argumentan que la plena implementación del TRIPS en los países en desarrollo estimularía la inversión

${ }^{48}$ Posición de UPOV basada en una intervención ante el Consejo del TRIPS, el 19 de septiembre de 2002, "International Harmonization is essential for effective plant variety protection, trade and transfer of technology" (disponible en: http://www.upov.org). Como veremos, UPOV promueve la armonización internacional como una herramienta indispensable para la protección de nuevas variedades vegetales.

${ }^{49}$ Propuesta de Bolivia, Brasil, Colombia, Cuba, República Dominicana, Ecuador, India, Perú y Tailandia, "The Relationship between the TRIPS Agreement and the CBD and the Protection of Traditional Knowledge-Elements of the Obligation to Disclose Evidence of Benefit-sharing under the Relevant National Regime", 18 March 2005 (WTO Document IP/C/W/442)

${ }^{50}$ South Centre \& CIEL, “IP Quarterly Update: First Quarter 2005”, p. 12.

${ }^{51}$ Council for TRIPS, "Review Of The Provisions Of Article 27.3(B)...”. 
en dichos países. En todo caso, se ha señalado que el acceso a las tecnologías protegidas debe ser parte de la distribución de los beneficios.

Por último, con respecto al otorgamiento de patentes sobre invenciones que han utilizado "conocimientos tradicionales" se ha identificado como área problemática la determinación de si dichas invenciones cumplen con el requerimiento de "novedad" exigido para otorgar este DPI. ${ }^{52}$ El problema se acentúa por la ausencia de información suficiente, por parte de los examinadores de solicitudes de patentes, respecto a la existencia de estos conocimientos. Se ha sugerido que el desarrollo de bases de datos sobre estos conocimientos, sumado a la exigencia de revelar el origen de los mismos al momento de solicitar una patente, podrían ayudar para solucionar estos problemas. Con respecto al consentimiento informado previo y a la distribución de los beneficios, diversas sugerencias se han presentado para enfrentar el problema del uso de estos conocimientos sin la autorización de las comunidades de origen y, por consiguiente, sin un acuerdo de distribución de beneficios. Fuera del ya mencionado requisito de revelar el origen al momento de solicitar una patente, se ha propuesto explorar el uso de otras categorías de $\mathrm{DPI}^{53}$ o adoptar un sistema sui generis de protección; o incluso establecer sistemas basados en contratos bilaterales entre los titulares del conocimiento y quienes quieren acceder a él para su utilización. ${ }^{54}$

En cuanto a la UPOV, a pesar de que este organismo es de la opinión que el régimen jurídico aplicable al acceso a los recursos genéticos debe ser independiente de un régimen jurídico en materia de derechos de obtentor, puesto que persiguen objetivos distintos, considera que ambos regímenes deben ser compatibles y apoyarse mutuamente. En este sentido, sostiene que el "acceso a los recursos genéticos" es un requisito clave para el progreso sustentable en la obtención de nuevas variedades vegetales. Es así como considera que los obtentores necesitan libre acceso a todo el material que permita maximizar el uso de los recursos genéticos para el beneficio de la sociedad. ${ }^{55}$ En cuanto a la "revelación del origen", la promueve cuando ésta implique facilitar el examen del requisito de "distinción", 56 pero no la acepta como una condición adicional a las que establece UPOV para otorgar protección (que son los requisitos de novedad, distinción, homogeneidad, estabilidad, y una denominación en conformidad con el acuerdo). Con respecto al "consentimiento informado previo" incentiva los principios

52 Council for TRIPS, "The Protection Of Traditional Knowledge And Folklore...".

53 Se ha sugerido que fuera de las patentes, otros DPI como las marcas comerciales, las indicaciones geográficas o los derechos de autor podrían ser utilizados para proteger los conocimientos tradicionales.

${ }^{54}$ Se ha señalado que este sistema no sería suficiente puesto que los contratos resultan generalmente de negociaciones sostenidas entre partes que se encuentran en situaciones de desigualdad.

${ }^{55}$ Esta idea se ve reflejada en el concepto de las "excepciones al derecho del obtentor" que significa, de acuerdo con el artículo 5(3) del Acta de 1978, que no será necesaria la autorización del obtentor para emplear la variedad como origen inicial de variación con vistas a la creación de otras variedades, ni para la comercialización de éstas; o, en las palabras del artículo 15(1)(iii) del Acta de 1991, El derecho de obtentor no se extenderá a los actos realizados a los fines de la creación de nuevas variedades (...).

${ }^{56}$ El Artículo 7 del Acta de 1991 establece que Se considerará distinta la variedad si se distingue claramente de cualquier otra variedad cuya existencia, en la fecha de presentación de la solicitud, sea notoriamente conocida... 
de la transparencia y la ética, por lo que el acceso al recurso genético respectivo debe hacerse respetando el marco jurídico del país de origen, pero nuevamente señala que no puede establecerse como un requisito adicional para otorgar el derecho de obtentor. Finalmente, en materia de "distribución de beneficios", señala que UPOV tiene sus propios principios al respecto, tales como las excepciones o el privilegio del obtentor; la excepción para la investigación; ${ }^{57}$ la excepción para la subsistencia de los agricultores $;^{58}$ y el privilegio opcional en materia de derechos de los agricultores. ${ }^{59}$ Sostienen que cualquier otro mecanismo que se pueda introducir en materia de distribución de beneficios podría crear barreras innecesarias para progresar en las obtenciones de nuevas variedades. De lo anterior, podemos concluir que el enfoque de UPOV tiene por objeto promover la protección de los derechos e intereses de los obtentores, y es por eso que busca la armonización internacional y nacional basada en el sistema UPOV. ${ }^{60}$

Por último, las iniciativas de la OMPI con respecto a los recursos genéticos se han desarrollado, como ya señaláramos, a través de dos instancias diferentes de negociación. El Comité Intergubernamental y el Comité Permanente sobre el Derecho de Patentes.

El Comité Intergubernamental sobre Propiedad Intelectual y Recursos Genéticos incluye, dentro de su mandato, la posible adopción de un instrumento internacional en materia de DPI y recursos genéticos. ${ }^{61}$ La discusión de esta alternativa ha sido bastante controvertida y no se esperan resultados muy luego. Sin embargo, mientras dicha opción se discute, el Comité ha trabajado en torno a diversas materias que son relevantes para un régimen jurídico de acceso a los recursos genéticos, tales como el desarrollo de modelos de cláusulas para los contratos de acceso a los recursos genéticos que digan relación con la propiedad intelectual; 62 y la elaboración de un estudio para la CDB respecto a los "métodos, consistentes con las obligaciones emanadas de los tratados administrados por la OMPI,

\footnotetext{
57 Artículo 15(1)(ii), del Acta de 1991: El derecho de obtentor no se extenderá a los actos realizados a título experimental.

58 Artículo 15(1)(i), del Acta de1991: El derecho de obtentor no se extenderá a los actos realizados en un marco privado con fines no comerciales.

59 Artículo 15(2), del Acta de 1991: ... cada Parte Contratante podrá restringir el derecho de obtentor respecto de toda variedad, dentro de límites razonables y a reserva de la salvaguardia de los intereses legítimos del obtentor, con el fin de permitir a los agricultores utilizar a fines de reproducción o de multiplicación, en su propia explotación, el producto de la cosecha que hayan obtenido por el cultivo, en su propia explotación, de la variedad protegida...

${ }^{60}$ Con respecto a la conveniencia de promover una armonización en materia de DPI ver: Dutfield, G. \& Suthersanen, U., "Harmonisation or Differentiation in Intellectual Property Protection? The Lessons of History", Occasional Paper 15, Quaker United Nations Office, August 2004. Específicamente respecto a las opciones en materia de derechos de obtentores ver: Helfer, L., "Intellectual Property Rights in Plant Varieties: An Overview with Options for National Governments”, FAO Legal Papers \#31, July 2002. Un problema que puede derivar de la armonización en esta materia se refiere a que el regimen jurídico sobre derechos de obtentores puede verse aislado de un proceso de integración de los diversos elementos necesarios para un régimen coherente en materia de acceso a los recursos genéticos y distribución de sus beneficios.

${ }^{61}$ Una propuesta del Grupo de Países Africanos que incluye objetivos, principios y elementos de un possible instrumento internacional fue aceptado como base para futures discusiones del Comité (South Centre \& CIEL, "IP Quarterly Update: Second Quarter 2004", p. 10).

${ }^{62}$ WIPO, IGC, Eighth Session, Geneva, June 6 to 10, 2005, "Overview of the Committee's work on genetic resources”, p. 4. (Document WIPO/GRTKF/IC/8/9, April 20, 2005).
} 
para requerir la revelación del origen del recurso genético y los conocimientos asociados a este para otorgar una patente". 63

En cuanto al trabajo del Comité Permanente sobre el Derecho de Patentes, éste se encuentra negociando desde el 2001 un tratado sobre derecho sustantivo de patentes. Las negociaciones hasta ahora han sido conflictivas fundamentalmente a raíz de que algunos miembros (EE.UU., Japón y la Oficina Europea sobre Patentes) han propuesto focalizar las negociaciones en un número limitado de elementos, básicamente el "estado de la técnica", el "plazo de gracia", la "novedad" y la "actividad inventiva". Por otra parte, los países en desarrollo han rechazado este enfoque puesto que excluiría de la negociación ciertos elementos que son esenciales para ellos, como las "excepciones a la patentabilidad" o los requisitos de la "divulgación suficiente" y, además, no permitiría una discusión comprensiva del asunto. ${ }^{64}$ Como resultado de estos desacuerdos, para fines de 2004 no existía consenso respecto a un programa de trabajo para el Comité en esta materia. ${ }^{65}$ Durante la última reunión de junio del 2005, nuevamente no se lograron acuerdos al respecto. ${ }^{66}$

De todo lo anterior resulta evidente que las iniciativas de coordinación e integración en curso no se desarrollan exentas de controversias. Es más, incluso se podría decir que algunos de estos procesos muy probablemente no serán exitosos, al menos en el corto plazo. Sin embargo, podemos afirmar que estas iniciativas internacionales crean las condiciones, identifican las posibles áreas de conflicto y acentúan los aspectos comunes y pacíficos entre los instrumentos en juego, de manera que establecen un escenario favorable para lograr una implementación nacional coordinada y complementaria de los elementos relevantes para un sistema de acceso a los recursos genéticos.

${ }^{63}$ Decisión VI/24 de la CDB. El estudio fue presentado a la CDB en el 2004, pero con el carácter de un estudio técnico cuyo objeto era contribuir al debate y análisis en la materia pero que no reflejaba la posición de la OMPI.

${ }^{64}$ South Centre \& CIEL, “IP Quarterly Update: Third Quarter 2004”, p. 15.

${ }^{65}$ A raíz de esta situación, el Director General de la OMPI incentivó la realización de consultas oficiosas a comienzos del 2005 para tratar de resolver este conflicto. La siguiente declaración es fruto de dicho esfuerzo: ... los participantes acordaron que la OMPI debería abordar con premura los seis puntos siguientes con miras a desarrollar y codificar gradualmente el Derecho internacional de propiedad intelectual: el estado de la técnica, el plazo de gracia, la novedad, la actividad inventiva, la divulgación suficiente y los recursos genéticos. Estas cuestiones deberán ser abordadas en procesos paralelos y acelerados, a saber, los cuatro primeros puntos (estado de la técnica, plazo de gracia, novedad y actividad inventiva) en el marco del SCP y los dos últimos (divulgación suficiente y recursos genéticos) en el marco del Comité Intergubernamental sobre Propiedad Intelectual y Recursos Genéticos, Conocimientos Tradicionales y Folclore. Tanto el SCP como el Comité Intergubernamental deberán elaborar un calendario y presentarse mutuamente informes sobre la marcha de los debates a ese respecto. (Declaración adoptada al término de las Consultas Oficiosas celebradas en Casablanca el 16 de febrero de 2005, Anexo del Documento WIPO/SCP/11/3, 7 de marzo, 2005).

${ }^{66}$ Standing Committee on the Law of Patents, Eleventh Session, June 1 and 2, 2005, Summary by the Chair (Document WIPO/SCP/11/5, June 3, 2005). 


\section{Desafíos para ChILE EN LA ADOPCión DE UN RÉGIMEN NACIONAL DE ACCESO A LOS RECURSOS GENÉTICOS}

Chile es un país que cuenta con una biodiversidad de alto valor, en particular por su gran porcentaje de flora y fauna endémica, esto es, que tienen su origen única y exclusivamente en Chile. A pesar de que no existe un inventario exhaustivo de la diversidad biológica y genética nacional, a las especies catastradas se les atribuye un importante uso actual y potencial en materia alimenticia, medicinal y agrícola, por mencionar algunos. ${ }^{67}$ Cabe señalar que se han registrado diversos casos de bioprospección y uso de materiales genéticos chilenos por instituciones de investigación y empresas extranjeras, las que incluso han llegado a patentar productos obtenidos a partir de ellos, generando ganancias y beneficios nada despreciables para sus titulares. Algunos de los casos más conocidos son el de la murtilla que se estaría mejorando en Australia para diversos usos o el del hongo de la Isla de Pascua (Streptomyces hygroscopicus) del cual se extrajo el compuesto rapamicina, que evita rechazos en los pacientes transplantados. ${ }^{68}$

Sin embargo, y sabiendo que existen casos como los señalados, hasta la fecha Chile no ha adoptado una regulación nacional para el acceso a sus recursos genéticos y distribución de sus beneficios. Lo anterior no significa que no hayan existido algunas iniciativas tendientes a establecer un marco regulatorio al respecto. Los primeros esfuerzos se remontan a los años 1995 y 1996, cuando recién entraba en vigencia la CDB en nuestro país. ${ }^{69}$ Con posterioridad, a fines del Gobierno del Presidente Ricardo Lagos, se retomó la iniciativa entre los organismos públicos competentes sin que se llegara al término de dicho período a concretar una propuesta para la discusión parlamentaria. Actualmente no hay indicios de iniciativas en curso; sin embargo, vale la pena revisar cuál ha sido la posición de Chile en esta materia tanto a nivel de política nacional como internacional, durante la última década. ${ }^{70}$

\section{El nuevo escenario nacional a nivel de política pública. Una oportunidad para coordinar e integrar}

Durante el año 2003 el Gobierno adoptó tanto su "Estrategia Nacional para la Biodiversidad (ENB)" 71 como la "Política Nacional para el Desarrollo de la Biotecnología

${ }^{67}$ Al respecto ver: Manssur, M.I. \& Lasén, C. “Acceso a Recursos Genéticos. Chile en el contexto mundial”, Fundación Sociedades Sustentables, FIELD, Darwin Initiative, 2003.

${ }^{68}$ Ibid., p. 20.

${ }^{69}$ Un análisis sobre dicho proceso se puede revisar en Flores, L. \& Hervé, D., "Chile: Early Attempts to Develop Access and Benefit-Sharing Regulations", en Accessing Biodiversity and Sharing the Benefits: Lessons from Implementing the Convention on Biological Diversity, Editado por S. Carrizosa et al., IUCN Environmental Policy and Law Paper $\mathrm{N}^{\circ}$ 54, 2004, pp. 227-241.

${ }^{70}$ Chile es parte de la CDB desde 1994, del TRIPS desde 1995, de UPOV 1978 desde 1996 y de la Convención de París desde 1991.

${ }^{71}$ De acuerdo con la CDB todos los países deben elaborar una estrategia nacional para la conservación y utilización sostenible de la diversidad biológica. Chile cumplió con dicha obligación casi 10 años después de haber ratificado el convenio. 
(PNDB)”, ambas políticas que directamente dicen relación con el régimen aplicable a los recursos genéticos.

En efecto, la ENB establece dentro de sus líneas estratégicas el "asegurar la preservación de especies y del patrimonio genético" y, específicamente, el "adoptar marcos de regulación para el acceso a los recursos genéticos así como para la participación justa y equitativa de los beneficios derivados de su utilización". ${ }^{72}$ Además, sostiene que deben establecerse "mecanismos y procedimientos apropiados para evitar o reducir al mínimo los impactos ambientales del desarrollo de la biotecnología (...) y potenciar los beneficios derivados del patrimonio genético en especies nacionales de importancia alimentaria y medicinal". ${ }^{73}$ Por su parte, la PNDB, que tiene como propósito "impulsar el desarrollo y la aplicación de la biotecnología en Chile, especialmente en los sectores productivos basados en recursos naturales, con el fin de incrementar el bienestar y la calidad de vida de todos los chilenos y de contribuir a la generación de riqueza en el país, velando por la protección de la salud y la sustentabilidad ambiental", ${ }^{74}$ establece como uno de sus objetivos más importantes la adopción de un "marco regulatorio para la biotecnología". 75 De esta manera, tanto la ENB como la PNDB establecen dentro de sus objetivos esenciales la adopción de un marco regulatorio en la materia que establezca los principios generales que deben orientar el desarrollo de la biotecnología y que incluye tanto los elementos relativos al acceso y distribución de beneficios como aquellos relacionados con la legislación en materia de propiedad intelectual. ${ }^{76}$

Otro instrumento relevante de la política nacional está constituido por la Política Nacional de Agricultura (PNA), adoptada en el 2000, y que busca guiar el desarrollo de la agricultura chilena hasta el año 2010. Uno de sus objetivos consiste en mejorar

${ }^{72}$ Línea Estratégica $\mathrm{N}^{\circ} 2$ letra e) de la ENB.

${ }^{73}$ Línea Estratégica No 2 letra f) de la ENB. Con posterioridad (abril de 2005) se aprueba el Plan de Acción de País para la Implementación de la Estrategia Nacional de Biodiversidad 2004-2015, que incluye, dentro de las principales acciones a desarrollar por el Gobierno en esta materia, las siguientes: antes del 2006, la elaboración de dos proyectos de ley, uno relativo al acceso a los recursos genéticos nativos y otro relativo a la seguridad de la biotecnología; antes del 2010, la ratificación del TI/RFAA; la promoción del desarrollo de la biotecnología basado en recursos genéticos nativos y actividades nacionales de bioprospección; y la creación de bancos de germoplasma.

74 PNDB, p. 7.

${ }^{75}$ Esto no significa que en la actualidad no existan regulaciones en la materia, simplemente se refiere a que la normativa existente responde a necesidades productivas específicas y, por lo tanto, no constituye un marco regulatorio coherente y comprehensivo para la biotecnología. Es por ello que la PNDB propone el desarrollo de un nuevo marco regulatorio mediante dos tipos de iniciativas. La primera busca utilizar el actual conjunto de leyes pertinentes al ámbito biotecnológico para actuar por la vía reglamentaria y progresar en aquellas acciones que requieren de soluciones inmediatas (por ejemplo, en el ámbito de las autorizaciones sanitarias para uso alimentario de organismos genéticamente modificados). La segunda busca elaborar un proyecto de Ley Marco de la Biotecnología que favorezca el desarrollo de la biotecnología y que asegure una gestión adecuada de los riesgos sanitarios y ambientales. Esta última implica la modificación de la legislación en materia de propiedad industrial y obtenciones vegetales, para cumplir con TRIPS y UPOV 1991.

${ }^{76}$ Cabe señalar que el propio Gobierno se impuso un calendario para la elaboración de este marco regulatorio a través del Plan de Acción de Corto Plazo del Sector Público para llevar a efecto los principales lineamientos de la ENB que señalaba que se debía contar con un proyecto de ley enviado al Congreso antes del 2006, plazo que no se cumplió. 
la productividad de los recursos naturales a través de diversos mecanismos, entre los cuales menciona la valoración económica y protección de los recursos genéticos, reconociendo la creciente atracción que estos recursos nacionales generan en el mercado biotecnológico internacional. Con dicho objeto, promueve la elaboración de una política específica que permita tanto la protección de estos recursos como de los derechos de los agricultores para conservar y desarrollar innovaciones relacionadas. Refuerza también la necesidad de promover la investigación científica y tecnológica como una herramienta de valoración de dichos recursos. ${ }^{77}$ Por otro lado, la PNA se refiere a la necesidad de reforzar la legislación en materia de obtenciones vegetales y otros DPI con el objeto de promover la diversificación productiva y la participación de la agricultura rural en las exportaciones nacionales. ${ }^{78}$

Del contenido de los instrumentos señalados se puede concluir que el Gobierno ha tenido en cuenta, al momento de decidir adoptar un marco regulatorio para los recursos genéticos y la biotecnología, tanto la dimensión relativa a la protección y conservación de la biodiversidad como aquella que busca establecer las condiciones y herramientas para impulsar el desarrollo tecnológico nacional. La pregunta es si esta situación a nivel de política interna se verá reflejada en las correspondientes iniciativas legales que se desarrollen para implementarla.

Cabe señalar un factor adicional que seguramente va a impactar en el proceso de elaboración de un marco regulatorio en esta materia. Chile ha adquirido en los últimos años, a través de la suscripción de tratados bilaterales de libre comercio, diversas obligaciones en materia de propiedad intelectual. Por ejemplo, en el año 2003, en virtud del tratado con EE.UU., se obliga a ratificar UPOV 1991 antes del año 2009; ${ }^{79}$ y con respecto a la OMPI, se ha obligado a ratificar varios de sus tratados en los próximos años. Es posible que estas obligaciones resten flexibilidad a las autoridades nacionales al momento de adoptar un régimen jurídico para el acceso a los recursos genéticos y la distribución de sus beneficios.

\section{Las iniciativas legales nacionales en materia de acceso a recursos genéticos y biotecnología}

Hasta fines del 2005 el Gobierno trabajó en la elaboración de diversos anteproyectos de ley relacionados con los recursos genéticos y la biotecnología. Durante el año 2004 se inicia tanto la redacción de un anteproyecto de ley en materia de acceso a los recursos genéticos como uno que se refiere a la seguridad de la biotecnología. Por otro lado, se inicia también el proceso de modificar la legislación en materia de propiedad

77 Política Nacional para la Agricultura, período 2000-2010, p. 48.

78 Ibid., p. 75.

${ }^{79}$ Chile también se ha obligado a ratificar UPOV 1991 pero para el año 2007, a través de un tratado de libre comercio firmado en el 2003 con la European Free Trade Association (EFTA), que se encuentra vigente desde fines del 2004. 
intelectual para adaptarse a UPOV $1991,{ }^{80}$ y a algunos tratados de la OMPI que, como dijimos, constituyen obligaciones provenientes de la suscripción de tratados bilaterales de libre comercio.

De la información obtenida de las diversas reparticiones públicas que participaron en estos procesos paralelos, se puede deducir que existía cierta intención de integrar y armonizar los diferentes objetivos que persigue una legislación en materia de acceso y bioseguridad y otra en materia de propiedad intelectual. Lo anterior se concluye de los trabajos de coordinación desarrollados entre las diversas instituciones competentes en la materia. En efecto, el Ministerio de Agricultura (específicamente su Oficina de Estudios y Políticas Agrarias, ODEPA) en conjunto con la Comisión Regulatoria en materia de Biotecnología, adoptada en el contexto de la PNDB, lideró los grupos de trabajo en materia de acceso y seguridad de la biotecnología que incluyó a representantes de instituciones como el INIA, la CONAF y el SAG, del Ministerio de Agricultura, del Departamento de Propiedad Intelectual, SubPesca y SERNAPESCA, del Ministerio de Economía, de la Direcon del Ministerio de RREE; y de la CONAMA y CONICYT.

Sin embargo, la interrupción de estos procesos a fines del 2005 al parecer se produjo por falta de acuerdo entre las distintas instituciones participantes con respecto a algunos aspectos esenciales de un marco regulatorio en materia de acceso y de bioseguridad, tales como la titularidad de los recursos genéticos y la forma de distribución de los beneficios, en el primero; y la obligatoriedad del etiquetado de los organismos modificados genéticamente, en el segundo.

Los esfuerzos de coordinación desplegados en materia de acceso y bioseguridad no se vieron reflejados, sin embargo, en la discusión de las materias relacionadas con la propiedad intelectual. Probablemente esta situación se debió a que ya se encontraba en curso un proceso modificatorio de la ley de propiedad industrial para adaptarse al TRIPS. ${ }^{81}$ En todo caso, y a raíz de las obligaciones asumidas a través de los tratados de libre comercio que Chile ha suscrito, el país está obligado adaptar su legislación a UPOV 1991 y a ratificar e implementar varios de los tratados administrados por la OMPI, lo que significa que tendremos que adaptar nuestra legislación en materia de propiedad intelectual una vez más. Específicamente, el país deberá ratificar el Tratado de Cooperación en materia de Patentes ${ }^{82}$ antes de enero de 2007 y el tratado de Budapest

${ }^{80}$ Este proceso implica modificar la Ley $\mathrm{N}^{\circ} 19.342$ de 1994 que regula los Derechos de Obtentores sobre Nuevas Variedades Vegetales, que se ajusta a la Convención de UPOV 1978.

${ }^{81}$ En efecto, con fecha 11 de marzo de 2005 se publicó la ley N $\mathrm{N}^{\mathrm{0}} 19.996$, que modifica la Ley N 19.039 sobre Propiedad Industrial con el objeto de cumplir con las obligaciones contraídas por Chile en virtud del Acuerdo de Marrakech (que crea la OMC) y sus anexos (TRIPS). Sin embargo, la vigencia de esta ley se encuentra supeditada a la dictación de su reglamento.

82 Obligación adquirida a través del acuerdo de libre comercio con EFTA (Anexo XII, artículo 2) y el Acuerdo de Asociación con la UE (Artículo 170 b) iv). El acuerdo de libre comercio con EE.UU. también impone esta obligación, pero no establece un plazo para su cumplimiento. Sólo señala que las partes deben desarrollar "esfuerzos razonables" para ratificar ciertos tratados, entre los cuales se incluye el TCP. 
sobre el Reconocimiento Internacional del Depósito de Microorganismos a los fines del Procedimiento en materia de Patentes ${ }^{83}$ antes de enero de 2009.

Por otra parte, Chile se ha obligado a realizar todos los "esfuerzos razonables, mediante un proceso transparente y participativo, para elaborar y proponer legislación dentro de cuatro años desde la entrada en vigor de este Tratado, que permita disponer de protección mediante patentes para plantas a condición de que sean nuevas, entrañen una actividad inventiva y sean susceptibles de aplicación industrial". 84

A diferencia de los procesos relacionados con el acceso y la bioseguridad, el proceso de adaptación de la legislación nacional en estas materias es desarrollado exclusivamente por el Ministerio de Economía, sin la participación de las demás instituciones públicas competentes en materia de recursos genéticos y biotecnología.

\section{CONCLUSIONES}

El "desarrollo sustentable" es un concepto que reúne elementos tanto sustantivos como de procedimiento. ${ }^{85}$ Mucho se ha discutido acerca de la naturaleza jurídica de este concepto y de los elementos que lo integran, existiendo cierto consenso al menos en que se trata de un principio que busca que tres áreas distintas del derecho internacional (estas son el derecho internacional ambiental, el derecho internacional económico y el derecho internacional de los derechos humanos) se puedan integrar. ${ }^{86} \mathrm{La}$ tarea de la integración, sin embargo, no resulta nada de fácil, entre otras cosas, por la existencia de los siguientes factores: ${ }^{87}$ la forma de creación del derecho internacional, ${ }^{88}$ la existencia de comunidades

${ }^{83}$ Obligación contraída a través del Acuerdo de Asociación con la UE (artículo 170 c) iii) y el acuerdo de libre comercio con EFTA (Anexo XII, artículo 3).

${ }^{84}$ Acuerdo de Libre Comercio Chile-EE.UU., artículo 17.9.2.

${ }^{85}$ Los elementos sustantivos incluyen la utilización sustentable de los recursos naturales; la integración de la protección ambiental y el desarrollo económico; el derecho al desarrollo; y la búsqueda de la equidad en la asignación de los recursos (intra e intergeneracional). Los principales elementos de procedimiento se refieren a la participación pública en la toma de decisiones y a la evaluación del impacto ambiental (en Boyle, A. \& Freestone, D. (ed.), "International Law and Sustainable Development. Past Achievements and Future Challenges”, Oxford University Press, 1999, pp. 8-16).

${ }^{86}$ McGoldrick, D., "Sustainable Development and Human Rights: An Integrated Conception", en 45 International and Comparative Law Quarterly, 1996, pp. 796-797.

${ }^{87}$ Fuentes, X. \& Hervé, D., Capítulo Primero del proyecto de publicación "Desarrollo Sustentable: El Desafío de la integración entre medio ambiente, comercio y derechos humanos" (borrador de octubre de 2005).

${ }^{88}$ La forma de creación del derecho internacional no contribuye a la integración en el sentido que se encuentra, en gran medida, dominada por los países desarrollados (Fuentes, X., "International Law-Making in the Field of Sustainable Development. The Unequal Competition between Development and the Environment", en 2 International Environmental Agreements: Politics, Law and Economics, 2002, p. 115). 
epistemológicas al interior de cada una de las ramas del derecho involucradas ${ }^{89}$ y la fragmentación de los mecanismos de solución de controversias. ${ }^{90}$

Las iniciativas internacionales que hemos revisado en este trabajo buscan, precisamente, integrar normas y principios de diferentes ramas del derecho con el objetivo de establecer un régimen jurídico coherente para el acceso a los recursos genéticos y la distribución de sus beneficios. Por lo tanto, podemos afirmar que estos procesos reflejan la búsqueda del objetivo del desarrollo sustentable en un área bien específica como la de los recursos genéticos. Ahora bien, ¿cuáles son los efectos positivos de este proceso de integración del derecho internacional? Como adelantamos, la existencia de estas iniciativas permite, por lo menos, dar luces a las autoridades nacionales para una implementación más coordinada de los diversos instrumentos internacionales relevantes. En efecto, la identificación de los elementos que deben incluirse en un régimen jurídico para el acceso a los recursos genéticos y la distribución de sus beneficios debiera permitir a los países ${ }^{91}$ aprovechar las flexibilidades existentes en cada uno de estos tratados para lograr adoptar un sistema de acceso nacional consistente con sus obligaciones internacionales y con los elementos esenciales de dicho sistema.

La pregunta que surge es si Chile está consciente de la necesidad de integrar su legislación en materia de conservación y utilización de los recursos genéticos con su legislación en materia de propiedad intelectual, para lograr adoptar un régimen jurídico que favorezca tanto el desarrollo tecnológico nacional como la protección de sus recursos. No es posible aún dar una respuesta a esta pregunta. Sin embargo, hay antecedentes que dan pie para temer que la legislación sobre propiedad intelectual y las obligaciones adquiridas a través de los tratados de libre comercio sean vistas como elementos aislados de las futuras regulaciones relacionadas con el acceso a los recursos genéticos y la distribución de sus beneficios.

\section{BiBLiografía}

Anaya, J. "Los derechos de los pueblos indígenas", en La Protección Internacional de los Derechos Humanos en los Albores del S. XXI, F. Gómez ed., U. Deusto, Bilbao, 2003.

Boyle, A. \& Freestone. D. (ed.), "International Law and Sustainable Development. Past Achievements and Future Challenges”, Oxford University Press, 1999.

Commission on Intellectual Property Rights (CIPR), "Integrating Intellectual Property Rights and Development Policy", London, 2002.

${ }^{89}$ Lo que impide tener una visión más amplia del derecho internacional y tiende a beneficiar ciertas áreas específicas en desmedro de otras.

${ }^{90}$ La existencia en el derecho internacional de sistemas separados de solución de controversias tanto en materia comercial (el Organo de Solución de Controversias de la OMC) como de derechos humanos (las Cortes Europea e Interamericana de DDHH) y, en algunos casos, también ambientales (como el Tribunal del Mar) no favorece la integración de las distintas ramas del derecho involucradas.

${ }^{91}$ Valiéndose del artículo 30 de la Convención de Viena sobre Derecho de los Tratados que señala que éstos deben interpretarse de manera complementaria. 
CouncIL FOR TRIPS, "The Relationship Between the Trips Agreement and the Convention on Biological Diversity. Summary of Issues Raised and Points Made. Note by The Secretariat", 8 agosto 2002. WTO Document IP/C/W/368.

COUnCIL FOR TRIPS, "Review of the Provisions of Article 27.3.b). Summary of Issues Raised and Points Made. Note by the Secretariat", 8 de agosto de 2002 (WTO Document $\mathrm{IP} / \mathrm{C} / \mathrm{W} / 369)$.

COUNCIL FOR TRIPS, "The Protection of Traditional Knowledge and Folklore. Summary of Issues Raised and Points Made. Note by the Secretariat", 8 de agosto de 2002, pp. 1-11 (WTO Document IP/C/W/370).

Downes, D., "How Intellectual Property Could Be a Tool to Protect Traditional Knowledge", en 25 Columbia Journal of Environmental Law, 2000.

Dutfield, G., "Sharing the Benefits of Biodiversity: Access Regime and Intellectual Property Rights", Science, Technology and Development Discussion Paper N ${ }^{\circ}$ 6, Center for International Development and Belfer Center for Science and International Affairs, Harvard University, Cambridge, MA, USA, 1999.

Dutfield, G., "Intellectual Property Rights, Trade and Biodiversity", Earthscan Publications Ltd, London, 2000.

Dutfield, G. \& Suthersanen, U., "Harmonisation or Differentiation in Intellectual Property Protection? The Lessons of History", Occasional Paper 15, Quaker United Nations Office, August 2004.

Earth Negotiations Bulletin, Vol. 09 No. 268, Monday, 8 December 2003, International Institute for Sustainable Development, IISD.

Flores, L. \& Hervé, D., "Chile: Early Attempts to Develop Access and Benefit-Sharing Regulations", en Accessing Biodiversity and Sharing the Benefits: Lessons from Implementing the Convention on Biological Diversity, Editado por S. Carrizosa et al., IUCN Environmental Policy and Law Paper $\mathrm{N}^{\circ}$ 54, 2004.

Fuentes, X., "International Law-Making in the Field of Sustainable Development. The Unequal Competition between Development and the Environment", en 2 International Environmental Agreements: Politics, Law and Economics, 2002.

Helfer, L., "Intellectual Property Rights in Plant Varieties: An Overview with Options for National Governments", FAO Legal Papers \#31, July 2002.

Kruger, M., "Harmonizing TRIPS and the CDB: A Proposal from India", en 10 Minnesota Journal Global Trade, 2001.

Mann, H. \& Porter, S., "The State of Trade and Environment Law, 2003. Implications for Doha and Beyond", IIISD y CIEL.

Manzur, M.I. \& Lasén, C., "Acceso a Recursos Genéticos. Chile en el contexto mundial", Fundación Sociedades Sustentables, Field, Darwin Initiative, 2003.

MCGoldrick, D., "Sustainable Development and Human Rights: An Integrated Conception”, en 45 International and Comparative Law Quarterly, 1996.

Secretariat of CBD, "Handbook of the Convention on Biological Diversity, including its Cartagena Protocol on Biosafety", $3^{\text {rd }}$ Edition, Earthscan Publications, 2005.

South Centre \& CIEL, "Intellectual Property Quarterly Update", disponible en www.southcentre.org/info/sccielipquarterly

UNEP/CBD/WG-ABS/3/7, Report of the Ad hoc Open Ended WK on ABS on the work of its Third Meeting, 3 March 2005.

UNEP/CBD/COP/3/23, "The Convention on Biological Diversity and the Agreement on Traderelated Aspects of Intellectual Property Rights (TRIPS): Relationships and synergies”, 5 October 1996. 
UPOV, "Access to Genetic Resources and Benefit-Sharing. Reply of UPOV to the Notification of June 26, 2003, from the Executive Secretary of the Convention on Biological Diversity (CBD)", adoptado por el Consejo de UPOV en su sesión ordinaria $\mathrm{N}^{\circ} 37$ de 23 de octubre de 2003.

UPOV, "International Harmonization is essential for effective plant variety protection, trade and transfer of technology", intervención ante el Consejo del TRIPS, el 19 de septiembre de 2002.

WIPO, IGC, Eighth Session, Geneva, June 6 to 10, 2005, "Overview of the Committee's work on genetic resources”, p. 4. (Document WIPO/GRTKF/IC/8/9, April 20, 2005). 